Agronomy, Madison, Wisconsin. pp. 425-442.

13. Laflen, J.M., and W.C. Moldenhauer. 1979. Soil and water losses from cornsoybean rotations. Soil Sci. Soc. Amer. J. 43:1213-1215.

14. Lee, A.F.S., and J. Gurland. 1975. Size and power of tests for equality of means of two normal populations with unequal variances. J. Amer. Stat. Assoc. 70:933-941.

15. Logsdon, S.D., J.K. Radke, and D.L. Karlen. 1993. Comparison of alternative farming systems. I. Infiltration techniques. Amer. J. Alternative Agric. 8:15-20.

16. Luk, S.H. 1979. Effect of soil properties on erosion by wash and splash. Earth Surface Processes 4:241-255.

17. Miller, W.P., and M.K. Baharuddin. 1986. Relationship of soil dispersibility to infiltration and erosion of southeastern soils. Soil Sci. 142:235240.

18. Molope, M.B., I.C. Grieve, and E.R. Page. 1985. Thixotropic changes in the stability of molded soil aggregates. Soil Sci. Soc. Amer. J. 49:979-983.
19. National Research Council. 1989. Alternative Agriculture. Board on Agriculture. National Academy Press, Washington, D.C.

20. Oades, J.M. 1984. Soil organic matter and structural stability: Mechanisms and implications for management. Plant and Soil 76:319-337.

21. Perfect, E., B.D. Kay, W.K.P. van Loon, R.W. Sheard, and T. Pojasok. 1990. Factors influencing soil structural stability within a growing season. Soil Sci. Soc. Amer. J. 54:173-179.

22. Pojasok, T., and B.D. Kay. 1990. Assessment of a combination of wet sieving and turbidimetry to characterize the structural stability of moist aggregates. Canadian J. Soil Sci. 70:3342.

23. Reganold, J.P., L.F. Elliot, and Y.L. Unger. 1987. Long-term effects of organic and conventional farming on soil erosion. Nature 330:370-372.

24. SAS Institute, Inc. 1985. SAS User's Guide: Statistics, Version 5 Edition. Cary, North Carolina.

25. Tisdall, J.M., and J.M. Oades. 1982. Organic matter and water-stable ag- gregates in soils. J. Soil Sci. 33:141163.

26. Walter, N.F., G.R. Hallberg, and T.E. Fenton. 1978. Particle-size analysis by the Iowa State University soil survey laboratory. In G.R. Hallberg (ed). Standard Procedures For Evaluating Quaternary Materials in Iowa. Iowa Geological Survey, Iowa City. pp. 6174.

27. Weill, A.N., C.R. De Kimpe, and E. McKyes. 1988. Effect of tillage reduction and fertilizer on soil macro- and microaggregation. Canadian J. Soil Sci. 68:489-500.

28. Williams, B.G., D.J. Greenland, G.R. Lindstrom, and J.P. Quirk. 1966. Techniques for the determination of the stability of soil aggregates. Soil Sci. 101:157-163.

29. Wilson, H.A., and G.M. Browning. 1945. Soil aggregation, yields, runoff, and erosion as affected by cropping systems. Soil Sci. Soc. Amer. Proc. 10:51-57.

\title{
UPCOMING EVENTS
}

May is American Wetlands Month; questions, offers to help, and requests for materials should be directed to Jodi Sproul, Terrene Institute, 1717 K St., NW, \#801, Washington, D.C. 20006; (202)833-8317.

May 17-June 11, Sustainable Agriculture Production Systems in Developing Countries, and June 14-23, Sustainable Agriculture Study Tour, courses sponsored by the International Center of Agricultural and Resource Development, will be held at Colorado State University; contact: ICARD, B302 Clark Building, CSU, Fort Collins, CO 80523; (303)491-5865.

May 29.31, Naturopathic Herbal Medicine: Herbal Healing Wisdom for the Future, the Gaia Herb Symposium, 1993, will be held in Ashland, MA; contact 1993

\section{Farm Profiles Invited}

For its new department on alternative agriculture profiles, the $A J A A$ welcomes short articles describing farmers who have adopted interesting alternative practices. The articles should include five elements: a brief description of the farm; the problems that made the farmer look for an alternative approach and the reasons why the alternative seemed plausible; a summary of the basic principles behind the alternative (possibly in a sidebar if it interrupts the flow of text); a discussion of how well the alternative has worked; and a dis- cussion of the applicability of the alternative for other farms. The length should be 1500 to 2000 words.

Submissions must be accompanied by a release, signed by the farmer, giving permission for this material to be published in the American Journal of Alternative Agriculture. Vol. 3, No. 4, of the AJAA has a further description of the department (page 188); or query the editor for further information. Send submissions to the Editor, AJAA, 9200 Edmonston Road, Suite 117, Greenbelt, MD 20770-1551.
Gaia Herb Symposium, 62 Old Littleton Road, Harvard, MA 01451.

June 2-5, Agricultural Biotechnology: A Public Conversation about Risk, the fifth annual meeting of the National Agricultural Biotechnology Council, will be held in West Lafayette, IN; contact NABC, 159 Biotechnology Building, Cornell University, Ithaca, NY 14853-2703.

\section{Letters To The Editor Invited}

The AJAA welcomes letters, short or long, commenting on articles in this journal or sharing ideas likely to be of interest to other $A J A A$ readers. Since our space is limited, we do reserve the right not to publish all letters or, at times, to publish only excerpts from them. To take part in this exchange of ideas, write to: Editor, $A J A A, 9200$ Edmonston Road, Suite 117, Greenbelt, MD 20770-1551. 